\title{
Individually Tailored Palliative Care in a Rural Region: A Representative Chart Survey and Physicians' Experiences with Integrated Care
}

\author{
André Terhorst, Helena Albrecht, and Birgitta Weltermann \\ Institute for General Medicine, University Hospital Essen, University of Duisburg-Essen, Hufelandstraße 55, 45147 Essen, Germany \\ Correspondence should be addressed to Birgitta Weltermann; birgitta.weltermann@uk-essen.de
}

Received 19 September 2015; Revised 13 March 2016; Accepted 31 March 2016

Academic Editor: Moira O’Connor

Copyright @ 2016 André Terhorst et al. This is an open access article distributed under the Creative Commons Attribution License, which permits unrestricted use, distribution, and reproduction in any medium, provided the original work is properly cited.

Background. Dying at home represents a special challenge in rural areas. This representative study describes the palliative care for patients in a rural German region. Methods. In a cross-sectional, representative study all physicians of a large rural area were surveyed in terms of their palliative care for a biennial period. In prestructured interviews and chart reviews physicians, practices, and palliative care patients' characteristics were obtained. The data were matched with regional mortality data. Results. According to public data 463 inhabitants died during the biennial period: 248 patients (53.6\%) died outside the region's borders including all in-hospital patients, while 215 died within this territory (46.4\%). Of the latter, a total of 91 patients (42.3\%) received care by the 14 physicians surveyed (on average: 6.6 patients per physician). $89 \%$ of families were actively involved in care, especially in multigenerational family scenarios. If family members were not involved, nursing services were active instead. Significant predictors for dying at home were the wish to die at home, a cancer diagnosis, and having family support. Conclusions. This study shows a physician-based, individually tailored, rural palliative care approach which allowed the majority of patients to die at home. Families were documented as an important social resource.

\section{Background}

For their end of life, most patients wish to "live a meaningful life" [1] in their familiar setting with "dying at home" [2]. Currently, dying at home is realized for about $13-70 \%$ of patients, depending on the setting and available palliative care structures [3-8]. It has been repeatedly shown that structured palliative care home services increase the likelihood to die at home about 3- to 4-fold [9-11]. Various structures of care are developed to improve access to palliative home care $[8,11]$ spanning ambulatory nursing and palliative care services $[7,12]$, primary care facility-based interdisciplinary teams [13], and multidisciplinary, hospital-based in- and outpatient services $[9,10,14]$. However, access to programs is often restricted to patients with certain medical or social characteristics (e.g., cancer patients only [7, 9, 11, 14-16], at least one informal caregiver at home [8], and no need for 24-hour services) or rendered difficult due to long distances in rural areas [17]. The issue of fragmented palliative care services has been the subject of recent discussion [18]. As one solution, reframing of the core ideas of end- of-life care in the concept of integrated palliative care is gaining increasing attention [18]. This concept refocuses on the individual patient and calls for services being tailored to each individual's needs.

As in many other countries, palliative care is an evolving field in Germany. In this two-year, representative, retrospective study we analyze the palliative care in a rural German region representing a physician-based, integrated palliative care approach. Predictors for dying at home in this rural region and the palliative care situations in extended families typical for rural areas were analyzed from the perspective of integrated palliative care.

\section{Methods}

2.1. Study Design. In this cross-sectional, representative study all physicians of the largest physician district of the Kassenaerztliche Vereinigung Nordrhein (publically authorized 
TABle 1: Physician characteristics $(n=15)$.

\begin{tabular}{|c|c|c|}
\hline & $N$ & $\%^{*}$ \\
\hline \multicolumn{3}{|l|}{ Physician characteristics } \\
\hline Licensed for the survey region & 15 & 100.0 \\
\hline Participated in survey & 14 & 93.3 \\
\hline Cared for palliative care patients in the biennial period & 13 & 86.7 \\
\hline \multicolumn{3}{|l|}{ Gender } \\
\hline Male & 11 & 78.6 \\
\hline Female & 3 & 21.4 \\
\hline Age, in years (average, SD, range) & $50.6(6.1)$ & $40-62$ \\
\hline \multicolumn{3}{|l|}{ Specialty } \\
\hline Family or internal medicine & 11 & 73.3 \\
\hline Other specialties & 4 & 26.7 \\
\hline \multicolumn{3}{|l|}{ Practice type } \\
\hline Solo practice & 8 & 57.1 \\
\hline Group practice & 6 & 42.9 \\
\hline Palliative patients per physician (average, SD, range) & $6.5(3.7)$ & $0-10$ \\
\hline Physician home visits in end-of-life period (average, SD, range) & $10.4(6.1)$ & $1-31$ \\
\hline Distance from physician practice to patient, in kilometers (average, SD, range) & $5.2(3.3)$ & $1-18$ \\
\hline \multicolumn{3}{|l|}{ Physician availability } \\
\hline $24 \mathrm{~h}$ availability for all patients of practice & 5 & 35.7 \\
\hline $24 \mathrm{~h}$ availability for selected patients of own practice & 3 & 21.4 \\
\hline Refers to palliative care patients to physician on duty when own office is closed & 6 & 42.9 \\
\hline
\end{tabular}

physicians' association), North Rhine-Westphalia, Germany, in the survey year 2009 were surveyed for their palliative care in the preceding two years.

In 2008 this rural area covered a territory of 164 square kilometers with a total of 27,780 inhabitants (population density per square kilometer: 169; for comparison: in North Rhine-Westphalia: 515) [19]. All fifteen physicians (eleven primary care and four specialist physicians (orthopedics, gynecology, pediatrics, and urology)) licensed for this area self-organize the mandatory regional acute care service. This service covers all after-office hours including nights and weekends except emergencies requiring an ambulance. It includes an on-call service for palliative care patients unless the patient's physician chooses to provide palliative care around the clock himself.

2.2. Data Collection. The study data were obtained in prestructured physician interviews performed by this physician. Each interview consisted of a cross-sectional physician survey and a retrospective analysis of the charts of all deceased palliative care patients that a physician had cared for during the years 2007-2008. All interviews were performed between May and July 2009.

The interviews were based on two prestructured survey instruments which requested the following information:

(1) Physician and practice sheet: for example, physician's age, gender, years in practice, medical specialty, practice size, physician's availability for his own palliative care patients, and physician's experiences with palliative care. For details see Table 1.
(2) Chart review sheet: during the chart-based interviews the physicians answered the various questions about each of their deceased palliative care patients: for example, age, gender, primary diagnosis, additional diagnoses relevant to palliative care, location where the patient was cared for, hospital days if required, place of death, and patient's wishes for end-of-life care; involvement of family members; physician's activities including the number of home visits, issues discussed with patient and family, and details on the medical care provided. At the end of each chart interview the physician was asked for his personal experiences in the palliative care for this patient and challenges faced. For details see Tables 2-5.

Using regional public mortality data the percentage of patients who had received palliative care by one of the physicians involved in relation to all the deceased in this biennial period was calculated. Based on registry data on the place of death, the percentage of palliative care patients who died at home in relation to all who died was calculated.

2.3. Data Management, Statistical Analysis, and Ethics' Statement. The study design and data management were performed at the Institute for General Medicine, University of Duisburg-Essen, Essen, Germany. Participation in this retrospective study was voluntary. To maintain confidentiality the physician interviewer did not have access to the patients' charts which were under review by the physician who had provided medical care only. The Ethics Committee 
TABLE 2: Characteristics of palliative care patients $(n=91)$.

\begin{tabular}{|c|c|c|}
\hline & $N$ & $\%^{*}$ \\
\hline \multicolumn{3}{|l|}{ Gender } \\
\hline Male & 40 & 44.0 \\
\hline Female & 51 & 56.0 \\
\hline Age, in years (average, SD, range) & $70.9(16.8)$ & $6-98$ \\
\hline \multicolumn{3}{|l|}{ Health insurance } \\
\hline Statutory & 83 & 91.2 \\
\hline Private & 8 & 8.8 \\
\hline \multicolumn{3}{|l|}{ Nursing care insurance granted } \\
\hline None & 32 & 35.2 \\
\hline Level 1 & 18 & 19.8 \\
\hline Level 2 & 29 & 31.9 \\
\hline Level 3 & 12 & 13.2 \\
\hline \multicolumn{3}{|l|}{ Primary diagnoses } \\
\hline Carcinoma/hematologic malignancy & 56 & 61.5 \\
\hline Neurological disease & 18 & 19.8 \\
\hline Cardiac disease & 7 & 7.7 \\
\hline Pulmonary disease & 5 & 5.5 \\
\hline Renal insufficiency & 4 & 4.4 \\
\hline Hepatic disease & 1 & 1.1 \\
\hline \multicolumn{3}{|l|}{$\begin{array}{l}\text { Secondary diagnoses relevant for } \\
\text { palliative care** }\end{array}$} \\
\hline None & 39 & 42.9 \\
\hline COPD & 8 & 8.8 \\
\hline Cardiac disease & 6 & 6.6 \\
\hline Peripheral vascular disease & 5 & 5.5 \\
\hline Diabetes mellitus & 4 & 4.4 \\
\hline Dementia & 4 & 4.4 \\
\hline Stroke/epilepsy & 3 & 3.3 \\
\hline Obesity & 2 & 2.2 \\
\hline Dialysis & 2 & 2.2 \\
\hline Cachexia & 2 & 2.2 \\
\hline Alcoholic disease & 2 & 2.2 \\
\hline Ascites & 1 & 1.1 \\
\hline Nicotine drug dependency & 1 & 1.1 \\
\hline Other (e.g., deafness) & 12 & 13.2 \\
\hline \multicolumn{3}{|l|}{ Patient's wishes ${ }^{* *}$} \\
\hline No pain & 50 & 54.9 \\
\hline No unnecessary therapies & 39 & 42.9 \\
\hline To die at home & 26 & 28.6 \\
\hline No breathlessness & 10 & 11.0 \\
\hline No anxiety & 8 & 8.8 \\
\hline Wanting to die with dignity & 6 & 6.6 \\
\hline Christian services & 1 & 1.1 \\
\hline Aesthetic appearance & 1 & 1.1 \\
\hline
\end{tabular}

* means $\%$ unless marked otherwise; $* *$ means multiple answers possible.

of the University Clinic Essen, University of Duisburg-Essen, Germany, had agreed to this approach.

The statistical analyses were performed with IBM SPSS Statistics for Windows, Version 21.0 (Armonk, New York: IBM Corp.). The primary endpoint was the percentage of palliative care patients who died at home. Secondary endpoints were the frequencies of the various aspects of palliative care provided. Active involvement of the next of kin was defined as taking over five or more elements of palliative care. Univariate analysis, $\chi^{2}$-statistics, and a logistic regression model were used to determine predictors for dying at home. Statistical significance was assigned at the level of $p<0.05$.

\section{Results}

3.1. Physician Characteristics. All but one of the fifteen physicians volunteered for the study; the nonparticipating GP was not interested in this study (participation rate 93.3\%). The physicians' average age was 50.6 years, $87.6 \%$ were male, and $42.9 \%$ were working in a group practice. During the biennial period each physician cared for 6.5 patients on average, who required a mean of 10.4 home visits each in a distance of up to 18 kilometers from the physician's office. For details see Table 1.

\subsection{Palliative Care Patient Population and Public Mortality} Data. In the years 2007 and 2008 a total of 463 inhabitants of the region died: $215(46.4 \%)$ deceased within and 248 (53.6\%) outside the city limits. A total of $19.7 \%$ of all deceased inhabitants had received palliative care by the physicians surveyed (91 of 463). Dying at home was made possible for $60.4 \%$ (55 of 91) of these patients. In addition, all long-term nursing home residents died in their "second home" (13 of 91; $14.3 \%$ ), increasing the rate of patients dying at home to $74.7 \%$ (68 of 91). For details see Table 3.

3.3. Palliative Care Patient Characteristics. During the biennial study period one specialist physician did not have any palliative patient. Thus, data on 91 patients from thirteen physicians were analyzed. The mean age of the patients was 70.9 years (range: 6-98), and 56.0\% were female $(n=51)$. There was no access limitation to the services which addressed patients with cancer (61.5\%) and noncancer patients (38.5\%). Stratified by main diagnosis, patients with malignancies ( 40 of 56; 71.4\%) and neurological diseases (11 of $18 ; 61.1 \%$ ) were most likely to die at home, followed by those with cardiac ( 4 of $7 ; 57.1 \%$ ), pulmonary $(2$ of $5 ; 40 \%)$, and renal diseases $(2$ of $4 ; 50 \%)$. One patient with a hepatic disorder died apart from home. For details see Tables 2 and 3.

At the time when a physician considered the patient to receive palliative care, $41.8 \%$ of the patients were unable to work and bedridden some time of the day $(n=38)$. The most frequent patient preferences for palliative care were not to suffer from pain (54.9\%), to avoid unnecessary therapies (42.9\%), and to die at home (28.6\%). For details see Table 2.

3.4. Living Circumstances of Palliative Care Patients and Their Families. About $40 \%$ of the patients lived in two-generation and about $20 \%$ in three-generation households, while only $2 \%$ lived alone. The multigenerational households were typically found in farm houses in small villages or in isolated cottages in the countryside. During the terminal phase, $52.7 \%$ of the families changed the patient's living circumstances or their private living space to enable the patient to stay at home $(n=48)$, for example, bathroom reconstruction $(n=35$, $38.5 \%$ ) or moving the patient's bed into the family's living room $(n=9,9.9 \%)$. Two patients moved to a nursing home 
TABLE 3: Characteristics of end-of-life period ( $n=91$ patients).

\begin{tabular}{|c|c|c|}
\hline & $N$ & $\%^{*}$ \\
\hline \multicolumn{3}{|l|}{ Functional status when palliative care started } \\
\hline Bedridden, dependent & 10 & 11.0 \\
\hline Limited self-care, bedridden $>50 \%$ of time awake & 14 & 15.4 \\
\hline Unable to work $<50 \%$ time bedridden & 14 & 15.4 \\
\hline Able to work, some daily activities possible & 16 & 17.6 \\
\hline Normal activity possible & 37 & 40.7 \\
\hline \multicolumn{3}{|l|}{ Patient's location when palliative care started } \\
\hline Within town (village) & 26 & 28.6 \\
\hline Farm house beyond the towns' limits & 51 & 56.0 \\
\hline Nursing home or hospice & 14 & 15.4 \\
\hline \multicolumn{3}{|l|}{ Generations in household } \\
\hline Patient alone (with nursing support) & 2 & 2.2 \\
\hline One-generation household (e.g., partner) & 35 & 38.5 \\
\hline Two-generation household & 36 & 39.6 \\
\hline Three-generation household & 18 & 19.8 \\
\hline \multicolumn{3}{|l|}{ Hospital care } \\
\hline Hospital care required & 46 & 50.5 \\
\hline Temporarily & 19 & 34.5 \\
\hline \multicolumn{3}{|l|}{ Place of death } \\
\hline At home & 55 & 60.4 \\
\hline Nursing home or hospice in nursing home & 13 & 14.3 \\
\hline Hospital, rehabilitation facility, or hospital palliative care unit & 23 & 25.3 \\
\hline \multicolumn{3}{|l|}{ Symptoms requiring intervention ${ }^{* *}$} \\
\hline Weakness & 71 & 78.0 \\
\hline Loss of appetite & 65 & 71.4 \\
\hline Fatigue & 56 & 61.5 \\
\hline Pain & 50 & 54.9 \\
\hline Family problems & 40 & 44.0 \\
\hline Needing support with daily activities & 39 & 42.9 \\
\hline Nausea & 37 & 40.7 \\
\hline Shortness of breath & 32 & 35.2 \\
\hline Difficulties coping with situation & 32 & 35.2 \\
\hline Constipation & 25 & 27.5 \\
\hline Vomitus & 19 & 20.9 \\
\hline Wounds & 18 & 19.8 \\
\hline \multicolumn{3}{|l|}{ Medication during end-of-life care ${ }^{* *}$} \\
\hline Opioids WHO III & 60 & 65.9 \\
\hline Opioids WHO II & 19 & 20.9 \\
\hline Nonopioid analgesics & 60 & 65.9 \\
\hline Proton inhibitors & 62 & 68.1 \\
\hline Sedatives & 48 & 52.7 \\
\hline Laxatives & 38 & 41.8 \\
\hline Corticosteroids & 51 & 56.0 \\
\hline Neuroleptics & 16 & 17.6 \\
\hline Diuretics & 25 & 27.5 \\
\hline Antidepressants & 17 & 18.7 \\
\hline Cardiac medication & 12 & 13.2 \\
\hline Duration of palliative care, in months (average, $\mathrm{SD}$, range) & $5.3(4.2)$ & $0-20$ \\
\hline
\end{tabular}

$*$ means $\%$ unless marked otherwise; ** means multiple answers possible. 
TABLE 4: Care provided by next of kin $(n=91)$.

\begin{tabular}{lcc}
\hline & $N$ & $\%$ \\
\hline Family members helped with the following ${ }^{*}$ & & \\
Oral medications & 66 & 72.5 \\
Positioning & 54 & 59.3 \\
Providing liquids & 43 & 47.3 \\
Symptom control & 40 & 44.0 \\
Nutritional support & 39 & 42.9 \\
Urine and stool management & 38 & 41.8 \\
Injecting subcutaneous medications & 33 & 36.3 \\
Administrative arrangements & 16 & 17.6 \\
Bowel clearing & 15 & 16.5 \\
Physiotherapy & 13 & 14.3 \\
Wound care & 13 & 14.3 \\
Supply of oxygen/inhalation & 8 & 8.8 \\
Music therapy & 7 & 7.7 \\
Feeding tube management & 5 & 5.5 \\
Intravenous nutrition & 3 & 3.3 \\
Coordination of feeding tube management & 3 & 3.3 \\
Changing of urinary catheter & 3 & 3.3 \\
Art therapy & 2 & 2.2 \\
Dialysis & 2 & 2.2 \\
Next of kin involved in care & 81 & 89.0 \\
E aspects of care & 59 & 64.8 \\
\hline means multiple answers possible & &
\end{tabular}

or a hospice within a nursing home for end-of-life care. Most family members were actively involved in care: help with oral medications (72.5\%) and positioning (59.3\%). The most frequent medications were pain medications (opioids and nonopioid analgesics). For details see Tables 3 and 4 .

3.5. Physicians' Roles, Experiences, and Preferences in Endof-Life Care. In addition to providing typical medical care, physicians were actively involved in various other issues, such as help with administrative topics (44\%), emotional support of relatives (69.2\%), and spiritual support (14.3\%). In nearly $40 \%$ of the patients, physicians reported that they were needed to "be present as human being" ( $n=35$; 38.5\%). For details see Table 5 .

In the majority of scenarios the family members were seen as positive contributors $(n=76 ; 83.5 \%)$. In $20 \%$ of the cases, physicians were very satisfied with the collaboration with the professional nursing services $(n=21 ; 23.1 \%)$ but would have liked more support by family members $(n=8 ; 8.8 \%)$ and/or better communication with hospitals $(n=5 ; 5.5 \%)$. Nearly $20 \%$ complained about difficulties to receive benefits from the nursing care insurance and its medical advisory organization $(n=16 ; 17.8 \%)$. For details see Table 5.

3.6. Predictors for Dying at Home. In the univariate analyses the following four independent variables were significant predictors for dying at home: family members were actively involved in care $(p<0.001)$, cancer diagnosis $(p=0.007)$, palliative care in a farm outside the village $(p<0.001)$, and the patient's wish to die at home $(p=0.012)$. An inpatient stay during the palliative care period was a negative predictor for dying at home $(p<0.001)$. There was no influence of the patient's gender, age $(\leq />72$ years), and functional status. Multicollinearity was observed between the variable "palliative care in a farmhouse outside the village" and all other positive predictors, so that this variable was excluded from the final regression model. Thus, the following three positive predictors for dying at home were cancer diagnosis (Odds Ratio (OR) 4.07; 95\% confidence interval (CI) 1.2713.03), family members actively involved in care (OR 5.7, 95\% CI 1.81-18.25), and the patient's wishing to die at home (OR 5.54; 95\% CI 1.38-22.23). In contrast, a hospital stay during end-of-life care was a negative predictor for dying at home (OR 0.08; 95\% CI 0.02-0.29).

\section{Discussion}

Our representative study of rural palliative care in a German region showed that $60.4 \%$ of those patients receiving palliative care died at home according to their wishes. In contrast to many other palliative care settings, the approach described in our study is not prestructured externally but results from individually tailored palliative care self-organized by the locally licensed physicians under integration of family and nursing service resources.

4.1. Predictors for Dying at Home in Rural Regions. The percentage of patients who died at home in our study is well within the range of the $36-80 \%$ reported from other scenarios $[7,11,15,16]$. Our study confirmed the diagnosis of a malignancy, the wish to die at home, and next of kin actively involved in care as significant positive predictors for dying at home $[2,6,15,20]$. Just as in other studies, a hospital stay during end-of-life care was determined as a negative predictor for dying at home in our study $[2,8]$. Similar to the $31.3 \%$ reported by Fukui et al. [7], 34.5\% of the patients in our survey who died at home required a temporary hospital stay. While some studies found no difference between urban and rural areas $[3,7,11]$, others concluded that rural patients were less likely to die at home due to a lack of ambulatory services $[17,21,22]$. Although we did not compare urban and rural areas, our rate of $60 \%$ of patients dying at home is consistent with findings from other palliative care settings.

4.2. Setting-Tailored Rural Palliative Care and the Role of Multigenerational Families. The patients described in our study died in quite different rural settings, ranging from a single patient in his trailer home supported by a nursing service to multigenerational family scenarios in farm houses. In the latter scenario even $80 \%$ of our patients were able to die at home which we attribute to the patients' strong wish to remain within their family setting and an extraordinary commitment of the multigeneration families. The specific social structures in this rural area are obvious when comparing to nationwide statistics: $25 \%$ of the patients in our study lived in families spanning at least three generations as do only $0.5 \%$ of the general population [23]. Canadian and Australian studies describe family members of palliative 
TABle 5: Physicians' roles, preferences, and experiences $(n=91)$.

\begin{tabular}{|c|c|c|}
\hline & $N$ & $\%$ \\
\hline \multicolumn{3}{|l|}{ Physicians' roles* } \\
\hline Information on end-of-life course & 69 & 75.8 \\
\hline Coordination of care & 65 & 71.4 \\
\hline Emotional support of relatives & 63 & 69.2 \\
\hline Emotional support of the patient & 59 & 64.8 \\
\hline Help with administrative regulations & 40 & 44.0 \\
\hline Crisis intervention & 39 & 42.9 \\
\hline Being there as human being & 35 & 38.5 \\
\hline Answering questions on advanced directives & 26 & 28.6 \\
\hline Advice regarding palliative care unit transfer & 16 & 17.6 \\
\hline Spiritual support & 13 & 14.3 \\
\hline \multicolumn{3}{|l|}{ Physicians wishing for more support or better cooperation * } \\
\hline Health/nursing insurance and MDK & 16 & 17.6 \\
\hline Patients' family members & 8 & 8.8 \\
\hline Hospitals & 5 & 5.5 \\
\hline Physician peers & 3 & 3.3 \\
\hline Administrative issues & 2 & 2.2 \\
\hline Nursing services & 2 & 2.2 \\
\hline \multicolumn{3}{|l|}{ Physicians valuing the following aspects as particularly good* } \\
\hline Family members as positive contributors & 76 & 83.5 \\
\hline Feeling welcome in the patients home by the family members & 24 & 26.4 \\
\hline Care of nursing service & 21 & 23.1 \\
\hline Control of symptoms & 15 & 16.5 \\
\hline Patient able to die at home & 10 & 11.0 \\
\hline Cooperation of all involved parties & 6 & 6.6 \\
\hline Communication with family members & 4 & 4.4 \\
\hline Cooperation with hospital & 1 & 1.1 \\
\hline \multicolumn{3}{|l|}{ Problems during end-of-life care* } \\
\hline Next of kin not supportive & 11 & 11.0 \\
\hline Family members unable to help due to own mental or physical overburden & 7 & 7.7 \\
\hline Family members lacking interest & 2 & 2.2 \\
\hline Next of kin being additional stressor & 1 & 1.1 \\
\hline Reasonable therapies denied for religious reasons by a caregiver & 1 & 1.1 \\
\hline Disagreement on the concept of care with a relative who was also physician himself & 1 & 1.1 \\
\hline Moments of insecurity during palliative care* & 31 & 34.1 \\
\hline Due to own personal involvement & 6 & 6.6 \\
\hline Due to extraordinary support required & 5 & 5.5 \\
\hline Due to psychological situation, disease process, or lack of medication response & 5 & 5.5 \\
\hline
\end{tabular}

* means multiple responses possible.

care patients who reported that they felt burdened by being forced into providing palliative care [22] due to a shortage of professionals and long distances [17, 22]. In our study family members took part in the patient's care in $89 \%$ of the situations but nursing services supported $91 \%$ of these scenarios. This rate is much higher than the $26-51 \%$ nursing service involvement reported in other studies [3, 24, 25].

4.3. Physicians' Roles and Experiences in Rural Palliative Care. Several studies showed that patients wish to be supported by the same physician for their end-of-life care [26], which was realized for $43 \%$ of our study patients. In contrast to other structures of palliative care, which are predominantly nurse-driven [17, 22], the physicians are the key coordinators in our region who supported patients and next of kin in a comprehensive way. While the physicians reported mainly positive experiences with families and nursing services, they expressed a desire for better communication with hospital physicians and/or health care insurances. In the service structure surveyed the shift to palliative care is often not as clearcut as in situations where a shift to a specialized palliative care service is associated with a change of care provider. 
4.4. Conclusions, Limitations and Perspectives. Our retrospective survey of a rural physician-based, interdisciplinary care documented an integrated palliative care approach tailored to the patients' preferences and social situations. As one of the first reports we shed a special light on palliative care scenarios in social structures typical for rural regions and showed an extraordinary involvement of multigenerational families; yet further studies are of interest. As in other retrospective studies, we cannot exclude potential recall biases or socially expected answers on behalf of the participants. Future studies on such integrated care models [18] should include the perspectives of patients, caregivers, and nursing services.

\section{Abbreviations}

CI: Confidence interval

OR: Odds Ratio.

\section{Competing Interests}

The research project forms the basis of the doctoral thesis of André Terhorst. All other authors declare that there are no competing interests.

\section{Authors' Contributions}

André Terhorst developed the study question. Birgitta Weltermann developed the study idea, the study concept, and supervised the data management. André Terhorst helped in study design, performed the data collection and the data management, and supported the interpretation of the results and literature search. Helena Albrecht performed the literature search and the data analysis. Birgitta Weltermann and Helena Albrecht reviewed the literature and drafted the first version of the paper. All authors critically reviewed the first draft and provided feedback on it. All authors read and approved the final paper.

\section{Acknowledgments}

The authors would like to thank the participating physicians for providing their insights and expertise. They thank Christine Kersting, M.A., for her thorough review of the statistical analyses and her support in paper editing. Furthermore, they owe gratitude to their highly respected colleague Professor Dr. Martin Hermann, who supported the project from the start. Due to his enormous experience and engagement in palliative care, he was a highly valuable resource throughout the study.

\section{References}

[1] T. Sandsdalen, R. Hov, S. Høye, I. Rystedt, and B. WildeLarsson, "Patients' preferences in palliative care: a systematic mixed studies review," Palliative Medicine, vol. 29, no. 5, pp. 399419, 2015.

[2] B. Gomes and I. J. Higginson, "Factors influencing death at home in terminally ill patients with cancer: systematic," British Medical Journal, vol. 332, no. 7540, pp. 515-521, 2006.
[3] D. Goodridge, J. Lawson, D. Rennie, and D. Marciniuk, "Rural/urban differences in health care utilization and place of death for persons with respiratory illness in the last year of life," Rural and Remote Health, vol. 10, no. 2, article 1349, 2010.

[4] W. T. Gallo, M. J. Baker, and E. H. Bradley, "Factors associated with home versus institutional death among cancer patients in connecticut," Journal of the American Geriatrics Society, vol. 49, no. 6, pp. 771-777, 2001.

[5] J. Cohen, D. Houttekier, B. Onwuteaka-Philipsen et al., "Which patients with cancer die at home? A study of six European countries using death certificate data," Journal of Clinical Oncology, vol. 28, no. 13, pp. 2267-2273, 2010.

[6] L. C. Escobar Pinzon, M. Claus, K. I. Zepf, S. Letzel, and M. Weber, "Dying in rhineland-palatinate (Germany): preferred and actual place of death," Gesundheitswesen, vol. 75, no. 12, pp. 853-858, 2013.

[7] S. Fukui, J. Fujita, M. Tsujimura, Y. Sumikawa, and Y. Hayashi, "Predictors of home death of home palliative cancer care patients: a cross-sectional nationwide survey," International Journal of Nursing Studies, vol. 48, no. 11, pp. 1393-1400, 2011.

[8] T. T. Siew, "Influencing factors of place of death among home care patients with cancer in Taiwan," Cancer Nursing, vol. 25, no. 2, pp. 158-166, 2002.

[9] M. S. Jordhøy, P. Fayers, T. Saltnes, M. Ahlner-Elmqvist, M. Jannert, and S. Kaasa, "A palliative-care intervention and death at home: a cluster randomised trial," Lancet, vol. 356, no. 9233, pp. 888-893, 2000.

[10] I. R. McWhinney, M. J. Bass, and V. Orr, "Factors associated with location of death (home or hospital) of patients referred to a palliative care team," Canadian Medical Association Journal, vol. 152, no. 3, pp. 361-367, 1995.

[11] G. Chvetzoff, M. Garnier, D. Pérol et al., "Factors predicting home death for terminally ill cancer patients receiving hospitalbased home care: the Lyon comprehensive cancer center experience," Journal of Pain and Symptom Management, vol. 30, no. 6, pp. 528-535, 2005.

[12] M. Costantini, I. J. Higginson, L. Boni et al., "Effect of a palliative home care team on hospital admissions among patients with advanced cancer," Palliative Medicine, vol. 17, no. 4, pp. 315-321, 2003.

[13] H. Temkin-Greener, N. T. Zheng, and D. B. Mukamel, "Ruralurban differences in end-of-life nursing home care: facility and environmental factors," Gerontologist, vol. 52, no. 3, pp. 335-344, 2012.

[14] A. Rosenquist, K. Bergman, and P. Strang, "Optimizing hospital-based home care for dying cancer patients: a populationbased study," Palliative Medicine, vol. 13, no. 5, pp. 393-397, 1999.

[15] E. Gyllenhammar, E. Thoren-Todoulos, P. Strang, G. Ström, E. Eriksson, and M. Kinch, "Predictive factors for home deaths among cancer patients in Swedish palliative home care," Supportive Care in Cancer, vol. 11, no. 9, pp. 560-567, 2003.

[16] Y. Singer, Y. G. Bachner, P. Shvartzman, and S. Carmel, "Home death-the caregivers' experiences," Journal of Pain and Symptom Management, vol. 30, no. 1, pp. 70-74, 2005.

[17] C. A. Robinson, B. Pesut, and J. L. Bottorff, "Issues in rural palliative care: views from the countryside," Journal of Rural Health, vol. 26, no. 1, pp. 78-84, 2010.

[18] M. van der Eerden, A. Csikos, C. Busa et al., "Experiences of patients, family and professional caregivers with Integrated Palliative Care in Europe: protocol for an international, multicenter, prospective, mixed method study," BMC Palliative Care, vol. 13, article 52, 2014. 
[19] K. Wesel, R. Düsseldorf, and K. Mittelstadt, Kommunalprofil Hamminkeln, Stadt, Information und Technik, NordrheinWestfalen, Geschäftsbereich Statistik, 2009.

[20] S. Karlsen and J. Addington-Hall, "How do cancer patients who die at home differ from those who die elsewhere?" Palliative Medicine, vol. 12, no. 4, pp. 279-286, 1998.

[21] F. I. Burge, B. Lawson, and G. Johnston, "Where a cancer patient dies: the effect of rural residency," Journal of Rural Health, vol. 21, no. 3, pp. 233-238, 2005.

[22] L. M. Wilkes and K. White, "The family and nurse in partnership: providing day-to-day care for rural cancer patients," Australian Journal of Rural Health, vol. 13, no. 2, pp. 121-126, 2005.

[23] Statistisches Bundesamt, Wirtschaft und Statistik: Haushalte und Lebensformen der Bevölkerung. Ergebnisse des Mikrozensus 2011, Statistisches Bundesamt, Wiesbaden, Germany, 2012.

[24] C. M. Moinpour and L. Polissar, "Factors affecting place of death of hospice and non-hospice cancer patients," American Journal of Public Health, vol. 79, no. 11, pp. 1549-1551, 1989.

[25] R. Hunt and K. McCaul, "A population-based study of the coverage of cancer patients by hospice services," Palliative Medicine, vol. 10, no. 1, pp. 5-12, 1996.

[26] A. Milberg and P. Strang, "Met and unmet needs in hospitalbased home care: qualitative evaluation through open-ended questions," Palliative Medicine, vol. 14, no. 6, pp. 533-534, 2000. 


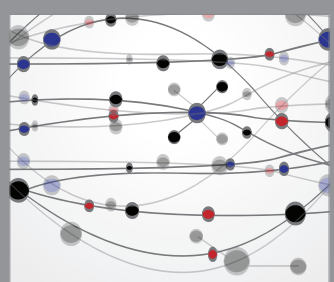

The Scientific World Journal
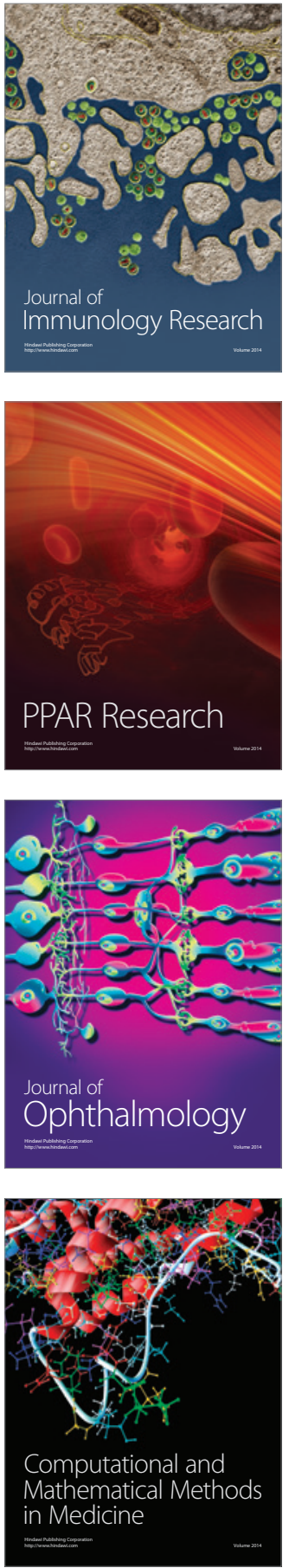

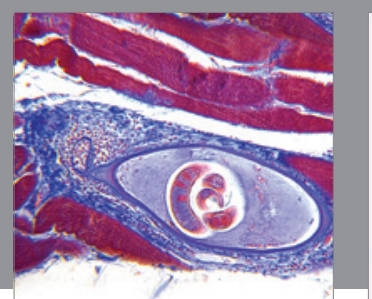

Gastroenterology Research and Practice

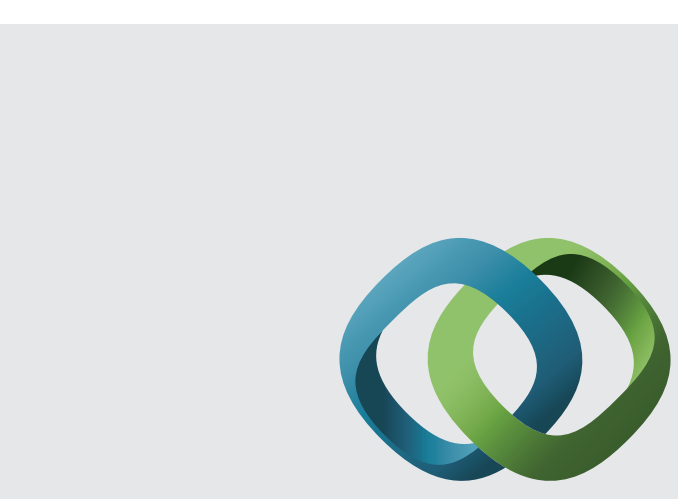

\section{Hindawi}

Submit your manuscripts at

http://www.hindawi.com
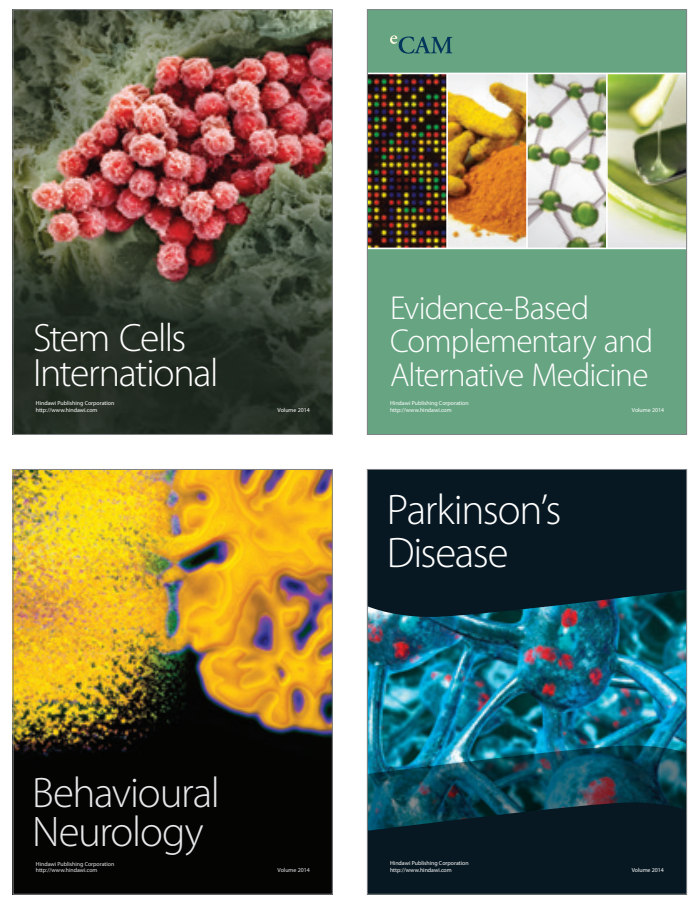
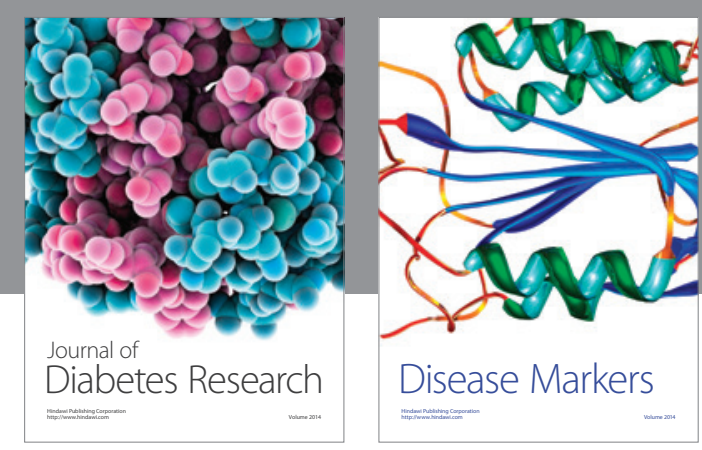

Disease Markers
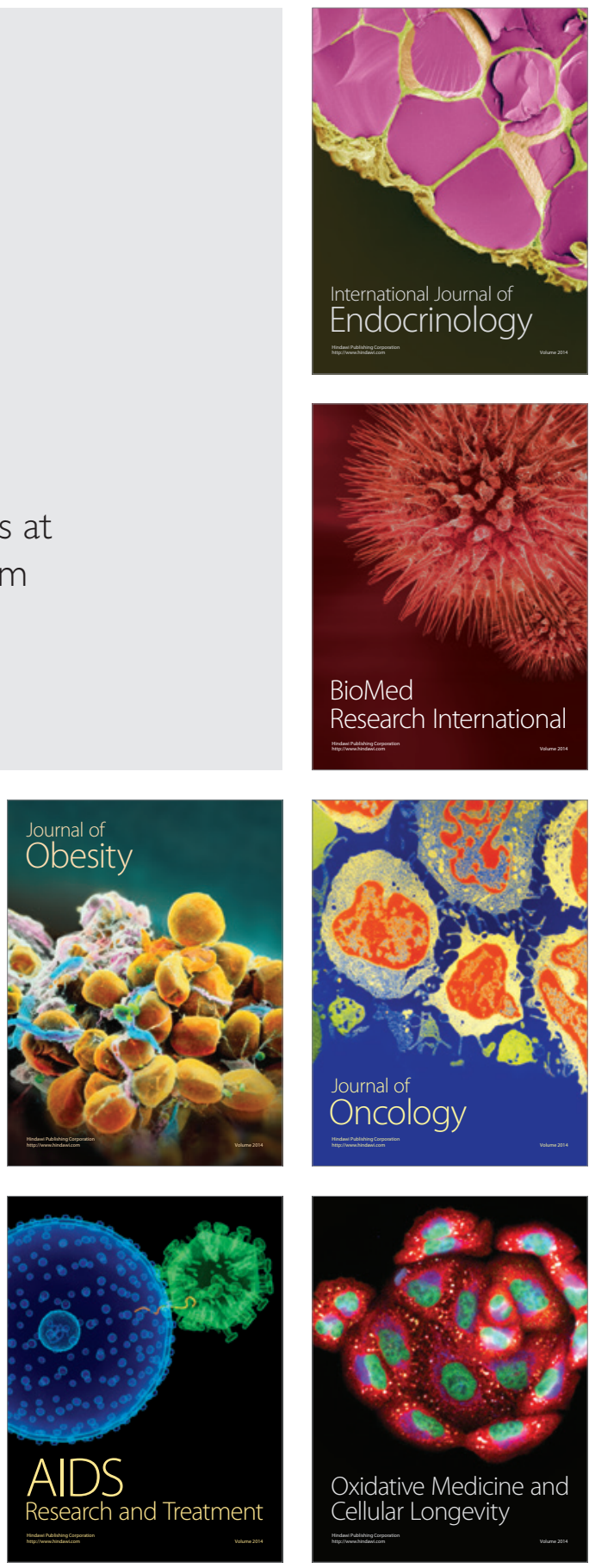